\title{
Visual analogue scale assessment of nasal obstruction might define patients candidates to spirometry*
}

\author{
Giorgio Ciprandi ${ }^{1}$, Maria Angela Tosca ${ }^{2}$, Alessio Signori ${ }^{3}$, Ignazio Cirillo ${ }^{4}$
}

\author{
Department of Internal Medicine, San Martino Hospital, Genoa, Italy \\ 2 Pneumology and Allergy Pediatric Unit, Istituto G. Gaslini, Genoa, Italy \\ 3 Department of Health Sciences, University of Genoa, Italy \\ 4 NavyMedicalCorps, La Spezia, Italy
}

SUMMARY

\begin{abstract}
Background: Asthma may be frequently associated with allergic rhinitis. Bronchial obstruction is a characteristic of asthma and spirometry is a cardinal step in asthma diagnosis. However, spirometry is rarely suitable in medical office. Visual Analogue Scales (VAS) is frequently used in common practice. Objective: This study aimed at evaluating the suitability of the use of VAS assessment of nasal obstruction to define patients with allergic rhinitis candidates for spirometry. Methods: 1728 patients with allergic rhinitis were consecutively evaluated. Clinical examination, skin prick test, VAS assessment, and spirometry were performed in all patients. Results: $7.9 \%$ of patients had impaired $F E V_{1}$ values and $24.5 \%$ had impaired $F E F_{25-75}$ values. A VAS value $<3.3$ might identify with good reliability patients with impaired $\mathrm{FEF}_{25-75}$ values, such as having initial bronchial airflow limitation. Conclusions: This study, performed in a large cohort of subjects, highlights the close link between upper and lower airways and shows the possible suitability of the use of nasal obstruction VAS assessment to define patients with allergic rhinitis candidates for spirometry.
\end{abstract}

Key words: allergic rhinitis, VAS, nasal obstruction, spirometry, $F E F_{25-75}$

\section{INTRODUCTION}

Allergic rhinitis is characterized by typical symptoms, induced by an IgE-mediated inflammatory response of the nose to the causal allergen exposure ${ }^{(1,2)}$. On the other hand, asthma is defined a chronic inflammation of the lower airways ${ }^{(3)}$. The allergic airway inflammation may therefore induce airflow limitations at both nasal and bronchial levels ${ }^{(4)}$. In this regard, a close link between allergic rhinitis and asthma has been widely reported ${ }^{(5,6)}$. Moreover, allergic rhinitis is a relevant risk factor for the onset of asthma ${ }^{(7)}$.

From a pathophysiological point of view, asthma is characterized by airflow obstruction ${ }^{(8,9)}$. Bronchial airflow may be easily assessed by spirometry. Several spirometric parameters may be considered, but $\mathrm{FEV}_{1}$ is considered the gold standard to detect asthma as stated by GINA (Global Initiative for Asthma) guidelines (www.ginasthma.com)

The WHO document 'the impact of allergic rhinitis on asthma' (ARIA) clearly underlines the role of allergic rhinitis as risk factor for asthma development or worsening and suggests of considering a possible bronchial involvement in all patients with allergic rhinitis ${ }^{(4)}$. Concerning this issue, a consistent epidemiological study reported that $\mathrm{FEV}_{1}$ may be impaired in about $5 \%$ of the patients with allergic rhinitis and perceiving nasal symptoms alone ${ }^{(10)}$. Moreover, slight spirometric impairment, such as reduced forced expiratory flow between $25 \%$ and $75 \%$ of vital capacity $\left(\mathrm{FEF}_{25-75}\right)$ values, may be frequently found in patients with allergic rhinitis and this parameter was thought a reliable marker of early bronchial involvement ${ }^{(11)}$. However, most otolaryngologists are not knowledgeable about the diagnostic benefits of spirometry, so it is rarely performed in ENT clinics.

Recently, the Visual Analogue Scales (VAS) have been proposed to easily assess symptoms in patients with allergic rhinitis ${ }^{(12)}$. VAS are quantitative measures largely validated in many diseases, for example for both chronic and experimental pain ${ }^{(13)}$. More recently, it has been reported that VAS assess- 
ment of breathlessness may be useful to measure the response to bronchodilation test ${ }^{(14)}$. In addition, it has been evidenced that VAS assessment of nasal obstruction was well correlated with rhinomanometry ${ }^{(15)}$. Therefore, VAS assessment of nasal obstruction might be used to have a rough idea of the nasal patency.

Until now there has been no study that compared VAS assessment of nasal obstruction with spirometric parameters in patients with allergic rhinitis. Therefore, the aim of the present study was to verify, in a large cohort of patients with allergic rhinitis, the suitability of the use of nasal obstruction VAS to define patient candidates for spirometry.

\section{METHODS}

\section{Study design}

This cross-sectional study included 1728 patients, with an age between 18 and 49 years and suffering from persistent allergic rhinitis. All of them were evaluated performing skin prick test, VAS assessment, and spirometry.

\section{Subjects}

A total of 1728 patients with persistent allergic rhinitis were consecutively evaluated. Demographic characteristics, including gender, age, and duration of rhinitis (expressed in years) were raised. All of them were Navy aspirants or sailors who had to refer to Navy Hospital for mandatory visit for obtaining or maintaining the health qualification (Navy IRB approved this methodology) and an informed consent was obtained from each patient.

A detailed clinical history was taken and a complete physical examination was performed. The patients were included in the study on the basis of a clinical history of persistent allergic rhinitis and presence of moderate-severe nasal symptoms according to validated criteria ${ }^{(4)}$. We excluded all the subjects who presented the following exclusion criteria: any prior documented history of asthma or presence of asthma symptoms, including cough, wheezing, dyspnoea, and shortness of breathing, acute or chronic upper respiratory infections, anatomical nasal disorders (i.e. nasal polyps, septum deviation, etc.), previous or current smoking (screened by expired-CO assessment during a single breath), previous or current specific immunotherapy, and use of nasal or oral corticosteroids, nasal or oral vasoconstrictors, anti-leukotrienes, and anti-histamines during the previous 4 weeks (if they assumed pharmacologic treatment, they were asked to return after stopping medications for 4 weeks).

All patients were treated only on demand with drugs alone. The diagnosis of persistent allergic rhinitis was made on the basis of a history of nasal symptoms and positive skin prick test according with validated criteria ${ }^{(4)}$.

\section{Skin prick test}

Skin prick testwere performed as stated by the European Academy of Allergy and Clinical Immunology ${ }^{(16)}$. The panel consisted of: house dust mites (Dermatophagoidesfarinae and pteronyssinus), cat, dog, grasses mix, Compositae mix, Parietariaofficinalis, birch, hazel, olive tree, Alternariatenuis, Cladosporium, Aspergilli mix (Stallergenes, Milan, Italy).

VAS assessment

VAS was used to assess the subjective feeling of respiration; it ranges from 0 (complete nose obstruction) to $10 \mathrm{~cm}$ (complete nose patency). Patients were asked to position a cross on a line corresponding to their own perception of respiration as previously reported ${ }^{(14,15)}$.

\section{Spirometry}

Spirometry was performed with a computer-assisted spirometer (Pulmolab 435-spiro 235, Morgan, England) and according to international guidelines ${ }^{(8,9)}$. Briefly, 3 blows (every 5 min) were performed and the best result was considered.

\section{Statistical analysis}

Data were described as median and 25th-75th percentiles for age, duration of rhinitis, VAS and values of $\mathrm{FEF}_{25-75}$ and $\mathrm{FEV}_{1}$ and as counts and percentages for gender and categorized $\mathrm{FEF}_{25-75}$ and $\mathrm{FEV}_{1}$. VAS assessment of nasal obstruction was expressed on a continue scale with a range of values from 0 to $10 ; \mathrm{FEF}_{25-75}$ at baseline was categorized as $\otimes 65 \%$ of predicted (abnormal values) and $>65 \%$ (normal values), $\mathrm{FEV}_{1}$ was categorized as $<80 \%$ (abnormal values) and $\geqq 80 \%$ (normal values). The rationale for choosing FEV1 $<80 \%$ predicted as cut-off reflects the GINA guidelines (www.ginasthma.com). The rationale for choosing $\mathrm{FEF}_{25-75}<65 \%$ predicted as cutoff derives from some recent studies that defined this value as abnormal ${ }^{(17-19)}$. Abnormal vs normal values for $\mathrm{FEF}_{25-75}$ and $\mathrm{FEV}_{1}$ were considered as distinct outcomes.

Multivariate logistic regression models were interpolated to valuate relation between outcomes and VAS and duration of rhinitis with age and gender considered as possible confounders and added in models. Moreover a ROC curve to testing validity of VAS as diagnostic test for $\mathrm{FEF}_{25-75}$ values was realized with lower values of VAS considered as 'positive' results of test. Optimally better cut-off of VAS to differentiating patients with abnormal $\mathrm{FEF}_{25-75}$ from patients with normal $\mathrm{FEF}_{25-75}$ was found. Best cut-off represented the value for which better classification of patients was realized with high value for both sensitivity and specificity.

Another ROC curve was made only on male and older patients where the median age was used as cut-off.

Area under curve (AUC) and 95\% CI were assessed. A value of $p<0.05$ was considered statistically significant. SPSS was used for computation.

\section{RESULTS}

Almost all the patients turned out to be younger than 26 years ( $90 \%$ of patients was 26 years old or younger) with a median age of 23 years $\left(25^{\text {th }}-75^{\text {th }}\right.$ percentile: $22-25$ years $)$ and a mean age of $24.5 \pm 5.6$ years. Of all, 1398 patients $(80.9 \%)$ were males, and the median duration of rhinitis was 4 years $\left(25^{\text {th }}\right.$ $75^{\text {th }}$ percentile: $2-8$ years). 


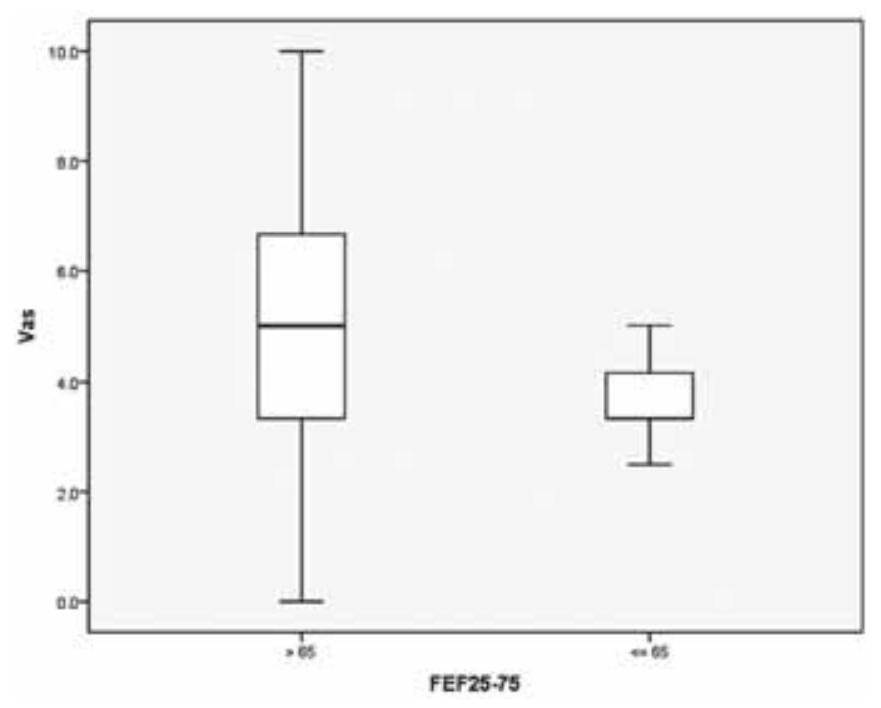

Figure 1. Boxplot of VAS for patients with normal and abnormal values of $\mathrm{FEF}_{25-75}$.

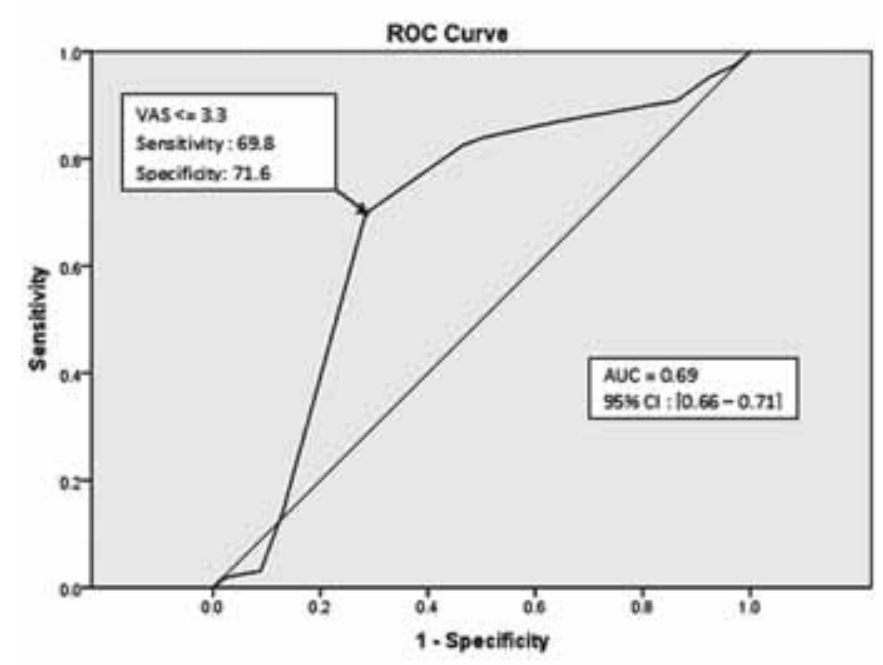

Figure 2. ROC curve for VAS assessment of nasal obstruction as diagnostic test and $\mathrm{FEF}_{25-75}$ as true outcome.

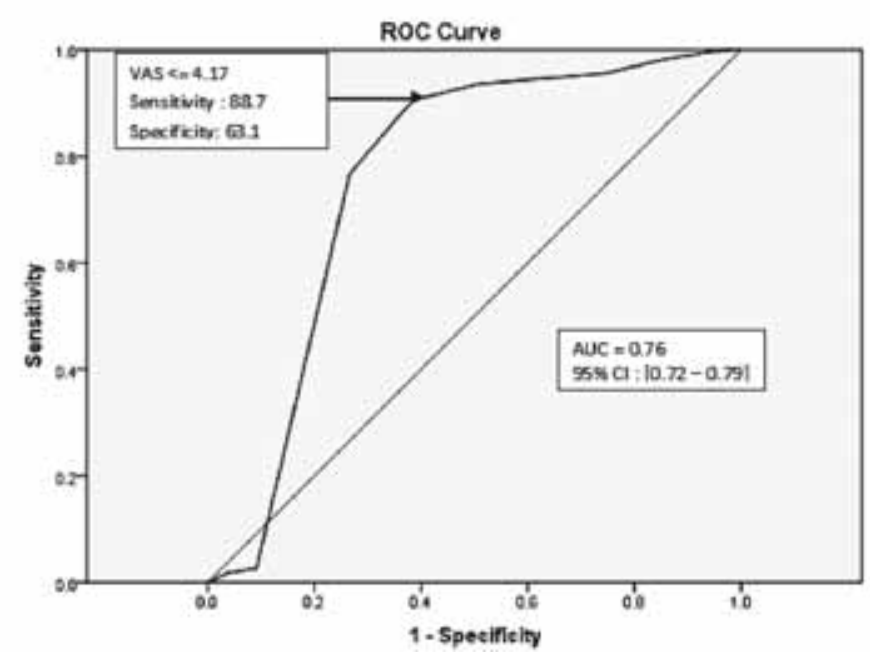

Figure 3. ROC curve for VAS assessment of nasal obstruction as diagnostic test and $\mathrm{FEF}_{25-75}$ as true outcome for only male and older patients.
The median value of VAS was $4.2\left(25^{\text {th }}-75^{\text {th }}\right.$ percentile: $3.3-6.7)$ as regarding spirometric variables median value for $\mathrm{FEF}_{25-75}$ was $71 \%$ of predicted $\left(25^{\text {th }}-75^{\text {th }}\right.$ percentile: $\left.66-73\right)$ and for $\mathrm{FEV}_{1}$ it was $90 \%$ of predicted $\left(25^{\text {th }}-75^{\text {th }}\right.$ percentile: $\left.83-95\right)$. Regarding $\mathrm{FEF}_{25-75}$, 424 patients $(24.5 \%$ ) had abnormal values, while 136 patients $(7.9 \%)$ had abnormal values for $\mathrm{FEV}_{1}$.

Table 1 shows the results of logistic regression with categorical $\mathrm{FEF}_{25-75}$ and $\mathrm{FEV}_{1}$ reported as distinct outcomes. For one-year increment on age, a statistically significant increased risk of about $6 \%(\mathrm{OR}=1.06 ; \mathrm{p}<0.001)$ to have abnormal values for $\mathrm{FEF}_{25-75}$ was found. VAS was statistically significant too and for one-unit increment on VAS scale a decreased risk to have abnormal values of $\mathrm{FEF}_{25-75}$ was revealed $(\mathrm{OR}=0.68 ; \mathrm{p}$ $<0.001$ ). Moreover, for one-year increment of rhinitis duration, a statistically significant increased probability to present abnormal values for $\mathrm{FEF}_{25-75}$ was found $(\mathrm{OR}=1.49$; $\mathrm{p}<$ $0.001)$.

In Figure 1, a boxplot for VAS in patients with abnormal and normal values of $\mathrm{FEF}_{25-75}$ is shown. Lower values on VAS scale were reported for patients with abnormal values of $\mathrm{FEF}_{25-75}$.

Concerning $\mathrm{FEV}_{1}$, age, gender and rhinitis duration were statistically significant, while VAS wasn't statistically significant. Particularly for one-year increment of rhinitis duration, an increased risk to present abnormal values for $\mathrm{FEV}_{1}$ was showed $(\mathrm{OR}=1.57 ; \mathrm{p}<0.001)$.

In Figure 2, a ROC curve of VAS as test to detect normal and abnormal values of $\mathrm{FEF}_{25-75}$ is shown. VAS was a fair test (Area Under Curve $=0.69$ ) with a discriminating cut-off, which could be represented by value 3.3 on VAS scale. For this value, the sensitivity of the test was $69.8 \%(95 \% \mathrm{CI}$ : [65.2-74.1]) that is the percentage of patients with $\mathrm{FEF}_{25-75} \leq 65 \%$ who had a value of VAS $\leq 3.3$ (296 patients of 424), while the specificity was $71.6 \%(95 \% \mathrm{CI}$ : [69 - 74]) corresponding with the percentage of patients with $\mathrm{FEF}_{25-75}>65 \%$ who had a value of VAS > 3.3 (933 patients of 1304).

In Figure 3, the same ROC curve, but for only male and older patients (older than 23 years) is shown. The AUC is higher (0.76; $95 \%$ CI: [0.72 - 0.79]) with a discriminating cut-off that could be represented by a value of 4.17 on the VAS scale. For this value, the sensitivity of the test was $88.7 \%$ (95\% CI: $84.3-$ $92.3)$, while the specificity was $63.1 \%$ (95\% CI: $58.5-67.5)$.

\section{DISCUSSION}

Allergic rhinitis and asthma might be considered as a single disorder involving two parts of the respiratory tract as was well documented by two elegant experimental studies ${ }^{(20,21)}$. Patients with allergic rhinitis may quite frequently present asthma symptoms and/or spirometric impairment. Indeed, impaired $\mathrm{FEV}_{1}$ values may be detected in some patients with allergic rhinitis, even though they perceive nasal symptoms alone ${ }^{(10)}$. Thus, this finding underlines the link between the upper and 
Table 1. Results of multivariate logistic regression for $\mathrm{FEF}_{25-75}$ and $\mathrm{FEV}_{1}$.

\begin{tabular}{|c|c|c|c|c|c|c|c|c|}
\hline & \multicolumn{4}{|c|}{$\mathrm{FEF}_{25-75}$} & \multicolumn{4}{|c|}{$\mathrm{FEV}_{1}$} \\
\hline & \multirow{2}{*}{ OR } & \multirow{2}{*}{$\mathrm{p}$} & \multicolumn{2}{|c|}{$95 \% \mathrm{CI}$ for OR } & \multirow{2}{*}{ OR } & \multirow{2}{*}{$\mathrm{p}$} & \multicolumn{2}{|c|}{$95 \% \mathrm{CI}$ for OR } \\
\hline & & & Lower & Upper & & & Lower & Upper \\
\hline Age & 1.06 & $<0.001$ & 1.03 & 1.09 & 1.14 & $<0.001$ & 1.11 & 1.17 \\
\hline Male & 1.31 & 0.16 & 0.90 & 1.90 & 3.05 & 0.014 & 1.26 & 7.40 \\
\hline VAS & 0.68 & $<0.001$ & 0.63 & 0.73 & 1.02 & 0.76 & 0.91 & 1.14 \\
\hline $\begin{array}{l}\text { Duration (per } \\
\text { year) }\end{array}$ & 1.49 & $<0.001$ & 1.43 & 1.55 & 1.57 & $<0.001$ & 1.45 & 1.70 \\
\hline
\end{tabular}

lower airways. In fact, the ARIA document suggests of carefully investigating bronchial involvement in all patients with allergic rhinitis ${ }^{(4)}$.

Moreover, airflow obstruction is a common pathway for both allergic rhinitis and asthma. In this regard, nasal obstruction may be considered the key symptoms in patients with allergic rhinitis ${ }^{(22)}$. In fact, the severity of nasal obstruction is significantly related to the nasal inflammation degree and bronchial function ${ }^{222}$. As VAS assessment of nasal symptoms is very simple and has been validated in allergic rhinitis ${ }^{(12,15)}$, the present study was designed to investigate the possible relationship between assessment of nasal obstruction by VAS and spirometry, in a large cohort of patients with allergic rhinitis. The aim was therefore to demonstrate whether VAS for nasal obstruction could be considered a simple tool for screening those patients with allergic rhinitis who may be candidate for spirometry.

This study provides evidence that a large percentage of patients with allergic rhinitis show impaired spirometric parameters, such as $7.9 \%$ had low $\mathrm{FEV}_{1}$ values ( $<80 \%$ of predicted) and $24.5 \%$ had low $\mathrm{FEF}_{25-75}$ values ( $\leqq 65 \%$ of predicted). It is to note that these patients did not refer previous bronchial symptoms. These findings substantially confirm previous reports ${ }^{(10,11)}$.

Some risk factors for impaired spirometry may be defined, mainly male gender for $\mathrm{FEV}_{1}$ and duration of rhinitis for both $\mathrm{FEF}_{25-75}$ and $\mathrm{FEV}_{1}$ values, confirming a previous study ${ }^{(23)}$.

Moreover, an inverse association between VAS and risk for abnormal values of FEF was revealed. In particular, a VAS value $\leqq 3.3$ may identify with a fair approximation patients with impaired $\mathrm{FEF}_{25-75}$ values ( $\leqq 65 \%$ of predicted), such as subjects with initial airflow obstruction. In addition, each VAS unit decrement determines a $30 \%$ increase of the risk of having impaired $\mathrm{FEF}_{25-75}$ values. In other words: more nose obstruction is perceived more probably $\mathrm{FEF}_{25-75}$ values may be impaired. Therefore, VAS assessment of nasal obstruction might be a simple tool that may be performed in each doctor's office and it might easily suggest todefine patients with allergic rhinitis candidates for spirometry, such as they perceiving a nasal obstruction with a VAS value $\leqq 3.3$. Moreover, this study identified a better cut-off in a sub-group of subjects, such as males and older, that corresponded to a VAS value $<4.1$. This message might be particularly relevant to early detect patients prone to become asthmatic, so it is possible adequately manage them for preventing dangerous sequelae.

\section{REFERENCES}

1. Christodoulopoulos P, Cameron L, Durham S, Hamid Q. Molecular pathology of allergic disease. II Upper airway disease. J Allergy Clin Immunol. 2000; 105: 211-223.

2. Ciprandi G, Vizzaccaro A, Cirillo I, Tosca MA, Massolo A, Passalacqua G. Nasal eosinophils display the best correlation with symptoms, pulmonary function and inflammation in allergic rhinitis. Int Arch Allergy Immunol. 2005; 136: 266-272.

3. Fahy JV. Eosinophilic and neutrophilic inflammation in asthma: insights from clinical studies. Proc Am Thorac Soc. 2009; 6: 256259.

4. Bousquet J, Van Cauwenberge P, Khaltaev N. Allergic rhinitis and its impact on asthma. J Allergy Clin Immunol. 2001; 108 (5 Suppl): S147-S334.

5. Bugiani M, Carosso A, Migliore E, et al. Allergic rhinitis and asthma comorbidity in a survey of young adults in Italy. Allergy. 2005; 60: 165-170.

6. Asher I. ISAAC International Study of Asthma and Allergies in Childhood. Pediatr Pulmonol. 2007; 42: 100.

7. Plaschke PP, Janson C, Norrman E. Onset and remission of allergic rhinitis and asthma and the relationship with atopic sensitization and smoking. Am J Respir Crit Care. 2000; 162: 920-924.

8. Pellegrino R, Viegi G, Brusasco V, et al. Interpretative strategies for lung function tests. Eur Respir J. 2005; 26: 948-968.

9. Miller MR, Hankinson J, Brusasco V, et al. Standardisation of spirometry. Eur Respir J. 2005: 26: 319-338.

10. Ciprandi G, Cirillo I, Vizzaccaro A, et al. Seasonal and perennial allergic rhinitis: is this classification adherent to real life? A population based study. Allergy. 2005; 60: 882-887.

11. Ciprandi G, Cirillo I, Klersy C, et al. Role of $\mathrm{FEF}^{25-75}$ as an early marker of bronchial impairment in patients with seasonal allergic rhinitis. Am J Rhinol. 2006; 20: 641-647.

12. Bousquet PJ, Combescure C, Neukirch F, et al. Visual analog scales can assess the severity of rhinitis graded according to ARIA guidelines. Allergy. 2007; 62: 367-372.

13. Price DD, McGrath PA, Rafii A, Buckingham B. The validation of visual analog scales as ratio scale measures for chronic and experimental pain. Pain. 1983; 17: 45-56.

14. Ciprandi G, Caimmi S, Marseglia GL, Tosca MA, Cirillo I. Visual Analogue Scale (V.A.S.) assessment of respiration might be a surrogate for spirometry in allergic rhinitis. J Biol Reg. 2010; 24: 103-105.

15. Ciprandi G, Mora F, Cassano M, Gallina AM, Mora R. V.A.S. and nasal obstruction in persistent allergic rhinitis. Otolaryngol HNS. 2009; 141: 527-529.

16. Dreborg S (Ed.). EAACI Subcommittee on Skin Tests. Skin tests used in type I allergy testing. Position Paper. Allergy. 1989; 44 (Suppl.10): 22-31. 
17. Simon MR, Chinchilli VM, Phillips BR, et al. Forced expiratory flow between $25 \%$ and $75 \%$ of vital capacity and $\mathrm{FEV}_{1}$ /forced vital capacity ratio in relation to clinical and physiological parameters in asthmatic children with normal FEV, values. J Allergy Clin Immunol. 2010; 126: 527-534.

18. Ciprandi G, Tosca MA, Signori A, Cirillo I. Bronchial hyperreactivity in patients with allergic rhinitis: $\mathrm{FEF}_{25-75}$ might be a predictive factor. Allergy Asthma Proc. 2011; 32: 4-8.

19. Ciprandi G, Cirillo I. FEF25-75 may be a marker of bronchial impairment in allergic rhinitis. J Allergy Clin Immunol. 2011; 127: 549-551.

20. Braunstahl GJ, Kleinjan A, Overbeek SE, et al. Segmental bronchial provocation induces nasal inflammation in allergic rhinitis patients. Am J Respir Crit Care Med. 2000; 161: 2051-2057.

21. Braunstahl GJ, Overbeek SE, Fokkens WJ, et al. Segmental bronchoprovocation in allergic rhinitis patients affects mast cell and basophil numbers in nasal and bronchial mucosa. Am J Respir Crit Care Med. 2001; 164: 858-865.
22. Ciprandi G, Cirillo I, Klersy C, et al. Nasal obstruction is the key symptom in hayfever patients. Otolaryngol Head Neck Surg. 2005; 133: 429-435.

23. Ciprandi G, Cirillo I, Pistorio A. Impact of allergic rhinitis on asthma: effects on spirometric parameters. Allergy. 2008; 63: 255-260.

\section{Giorgio Ciprandi, MD}

Semeiotica e Metodologia Medica I

Viale Benedetto XV 6

16132 Genoa

Italy

Tel: $+39-10-35331820$

Fax: +39-10-353 7573

E-mail: gio.cip@libero.it 